\title{
AGR-5/6/7 Operations Update for Technical Coordination Team April 2020
}

\author{
Joe Palmer
}

May 2020

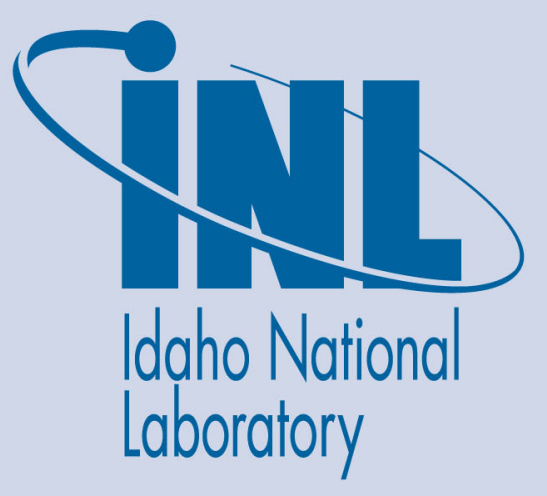

The INL is a U.S. Department of Energy National Laboratory operated by Battelle Energy Alliance 


\title{
AGR-5/6/7 Operations Update for Technical Coordination Team April 2020
}

\author{
Joe Palmer
}

May 2020

Idaho National Laboratory Idaho Falls, Idaho 83415

http://www.inl.gov

Prepared for the

U.S. Department of Energy

Under DOE Idaho Operations Office

Contract DE-AC07-05ID14517 


\section{AGR-5/6/7 Operations Summary Since Last TCT Meeting (Nov 2019)}

\section{Technical Coordination Team \\ April 23, 2020}

\section{Joe Palmer}

Mechanical Engineer, PE

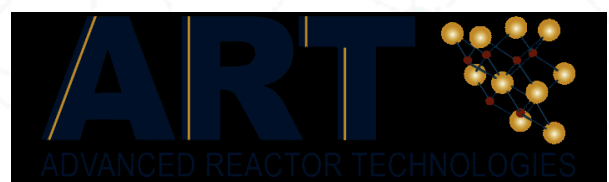




\section{Cycle 166B summary}

\section{ART:}

- During the last TCT meeting $(11 / 11 / 2019)$ we were at the beginning of cycle 166B. All capsules were isolated with a static gas blend of $94 \%$ neon.

- On $12 / 23 / 2019$ flow was initiated to capsules $2-5$ and temperature control commenced for capsules $3-5$ (capsule 2 was left at $94 \%$ neon because it had no surviving thermocouples).

- As flow was initiated, a surge in fission products was noted in the effluent of capsules $2-5$ (capsule 1 exhaust was kept closed). 


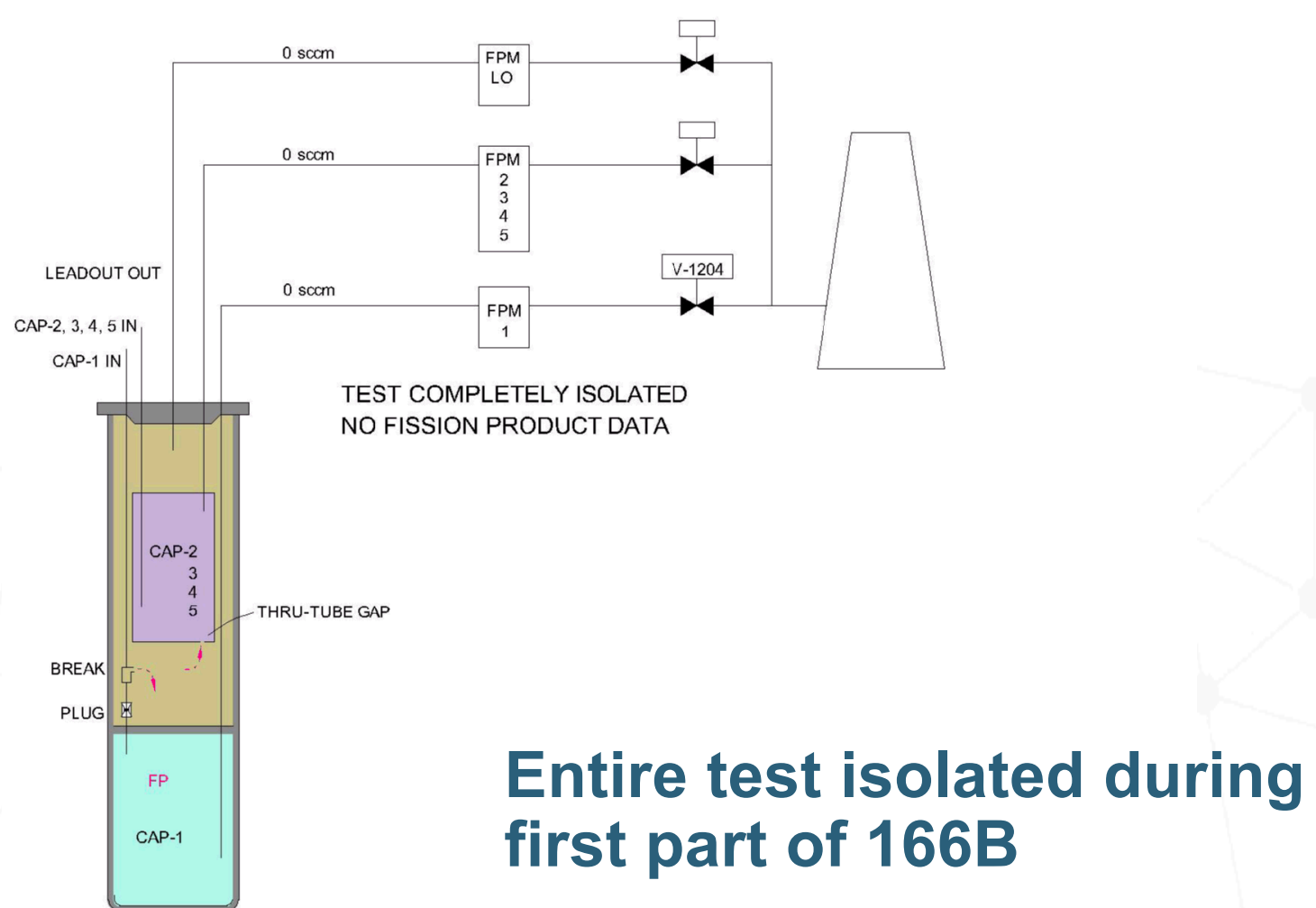




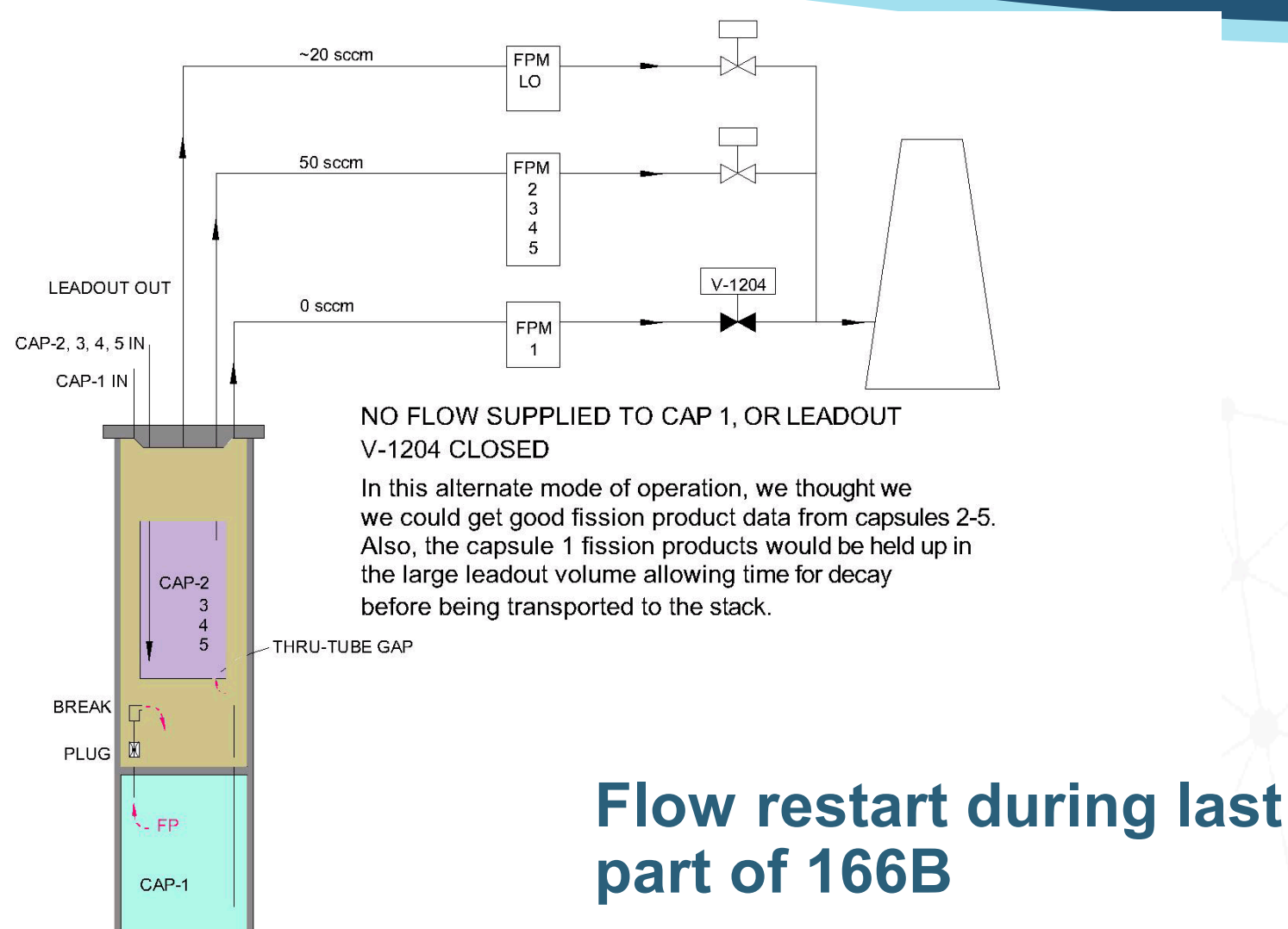




\section{Cycle 166B summary (cont)}

- Although the inlet and outlet valves to capsule 1 were left closed, we have seen evidence that there is a crack on the inlet line near the capsule (and maybe the outlet as well). This crack allows fission products to escape into the leadout.

- We arranged the capsule leakage flow to be from capsules into leadout, but it appears large amounts of fission products can make their way into capsules $2-5$ via "backstreaming". 


\section{Cycle 166B capsule 4 response to restarting flow}

\section{ART:}

Zoom Iday I wk 1mon All

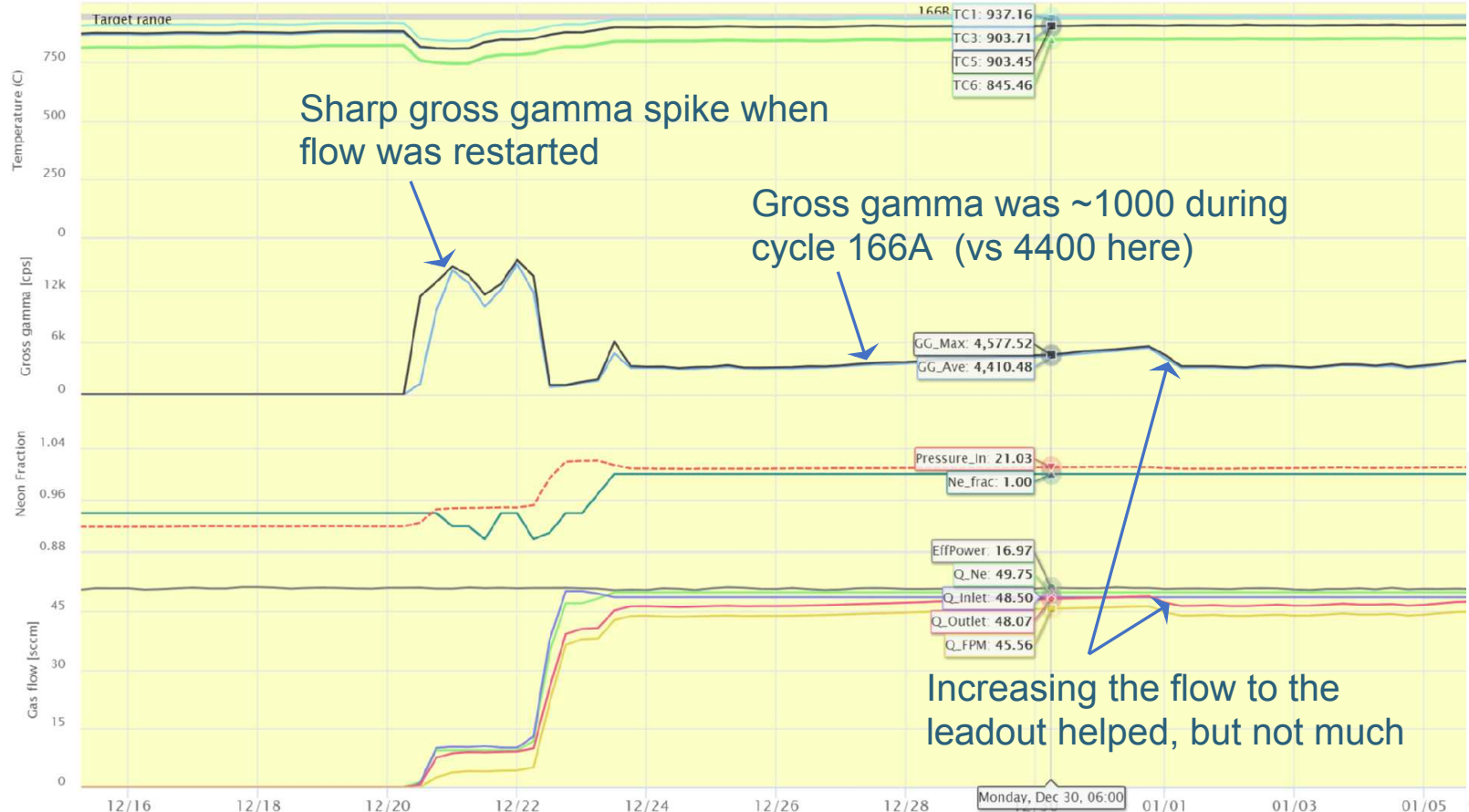




\section{ART:}

\section{Cycle 166B capsule 2 response to restarting flow}

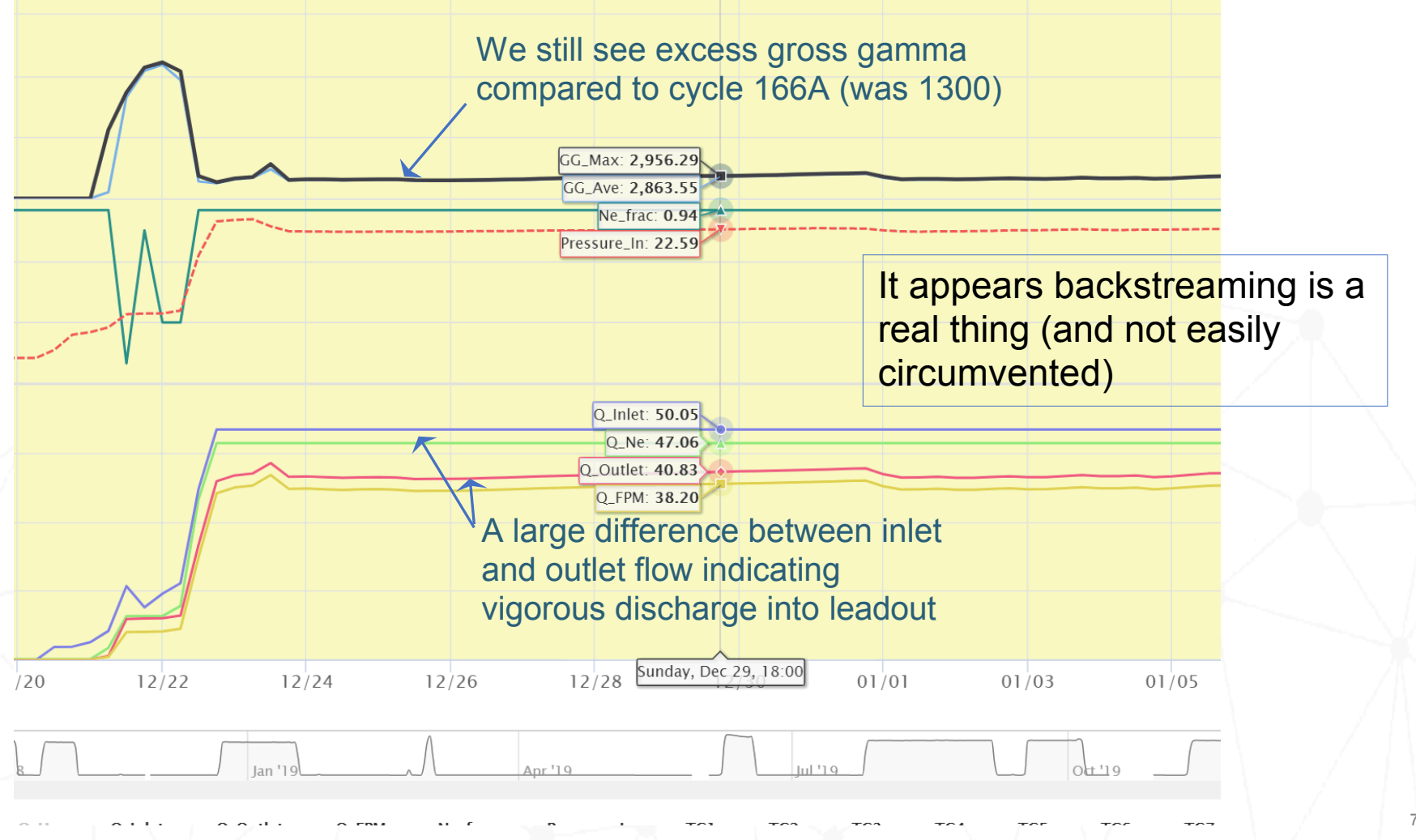




\section{ART:}

\section{Modeling of the backstreaming effect}

- Mitch Plummer prepared a model using a series of diffusion equations to help quantify the backstreaming effect.

- Backstreaming is proportional to Tgas ${ }^{3 / 2}$ (the gas temperature to the $3 / 2$ power) and increases by a factor of five between room temperature and $600^{\circ} \mathrm{C}$ (approximate temperature of thru-tubes where they pass through the capsule floor).

- As expected, backstreaming is also strongly affected by the velocity against which the atoms are moving 


\section{ART:}

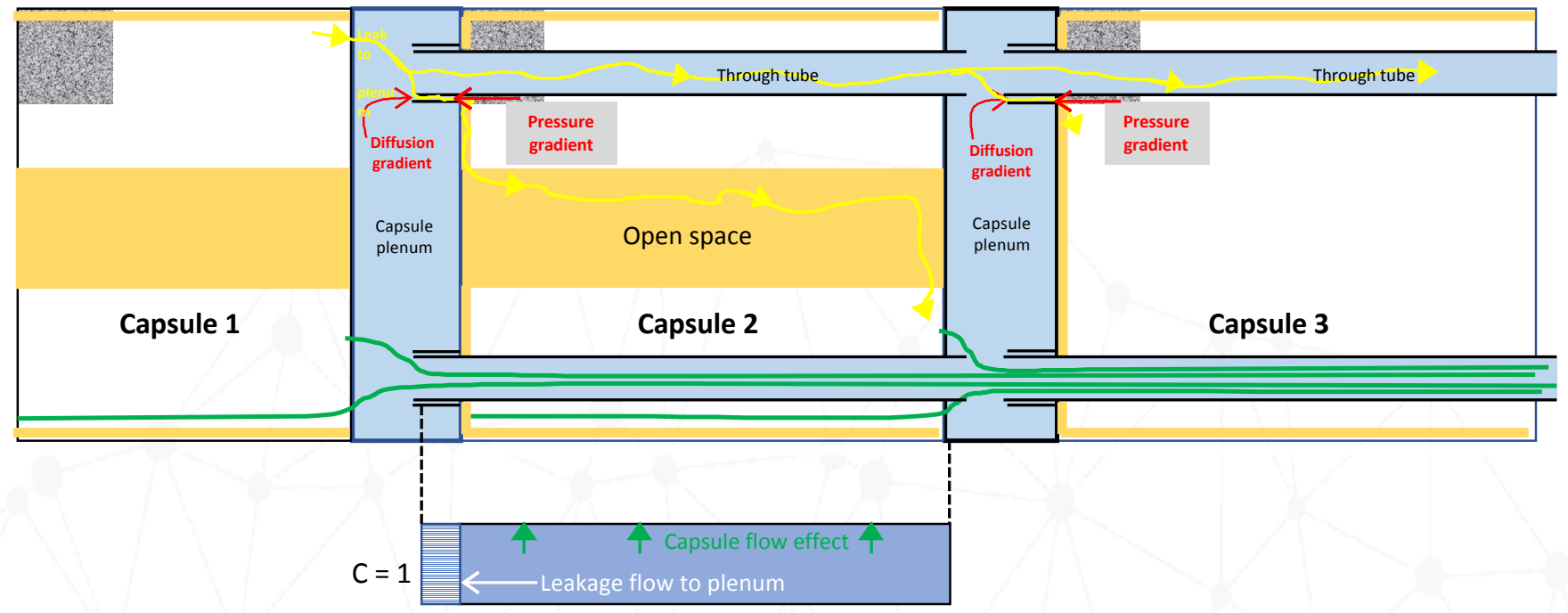

Solve for Neon concentration vs time, using advection-dispersion eq, with decay, and sink term for capsule throughflow

$$
\frac{d}{d t} c(x, t)=\theta(x) \cdot\left[\left(D \cdot \frac{d^{2}}{d^{2}} c(x, t)-v \cdot \frac{d}{d x} c(x, t)\right)-\lambda \cdot c(x, t)\right]-Q_{c a p} \cdot c(x, t)
$$




\section{ART:}

\section{Counter-current diffusion}

- Flow into capsules appears to reflect diffusion against the advective pressure gradient

Strong gradient (large difference, short distance) across slip-joint annulus

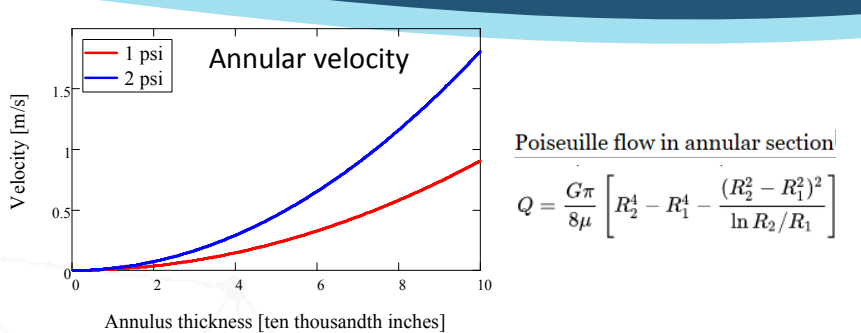

Gas velocity in annulus is non-linear function of annulus thickness

- Diffusion coefficient is proportional to temperature, $\left(\sim \mathrm{T}_{\text {gas }}{ }^{3 / 2}\right)$

- Model as diffusion against 'leakage' flow, with sink term for capsule flow.

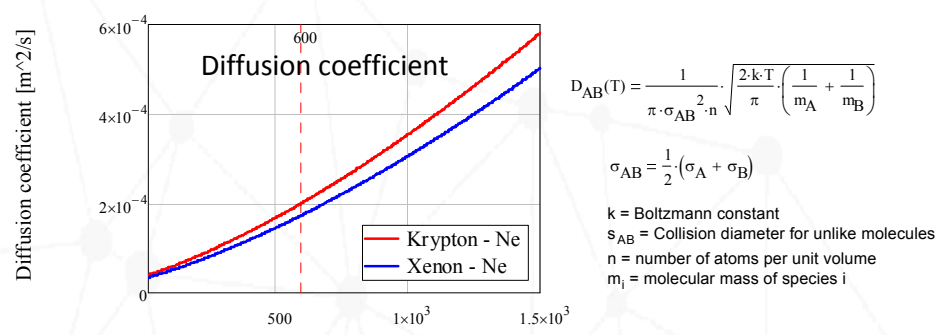

Temperature $\left[{ }^{\circ} \mathrm{C}\right]$

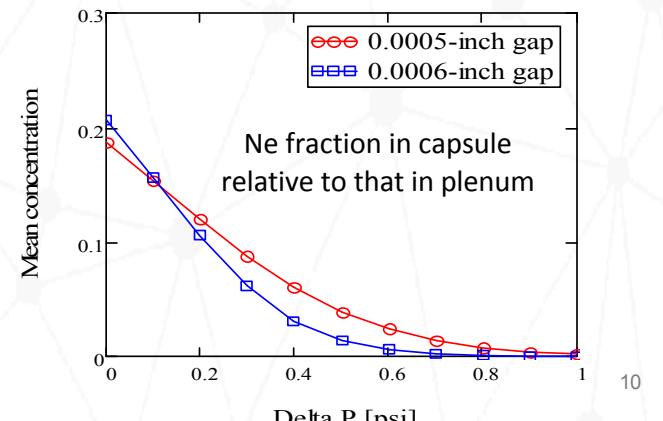




\section{ART:}

\section{Cycle 167A summary}

- A 220 liter delay tank was plumbed into the AGR-5/6/7 exhaust system during the 167A outage. After passing through the fission product monitors, the effluent from all capsules and the leadout are combined, then fed into the delay tank, and then on to the ATR stack. This delays the combined flow by $12-18$ hours depending on flow rate.

- After the delay tank was plumbed in, an effort was made to flush all lines and all fission product monitor traps. During this flushing period we were able to get a little flow through capsule 1 (about 1 sccm) for several days, and completely flushed this trap. 


\section{ART:}

\section{Cycle 167A summary (cont)}

- Cycle 167A was a mixed mode PALM cycle, with the first five days being at $5 \mathrm{MW}$ lobe power followed by 24 hours at $20 \mathrm{MW}$ lobe power.

- During the low power phase, we continued to be able to push about $1 \mathrm{sccm}$ through capsule 1, which kept the leadout clean and the gross gamma (GG) signatures of capsules 2-5 stayed low. However, with both the power and temperature way below normal, we're not totally sure what to make of this data.

-When the power came up to $20 \mathrm{MW}$, gross gamma on all capsules rose rapidly (far above cycle 166A) and the Capsule 1 outlet flow went to zero (on its own). 


\section{ART:}

\section{Capsule 4 gross gamma during Cycle 167A}

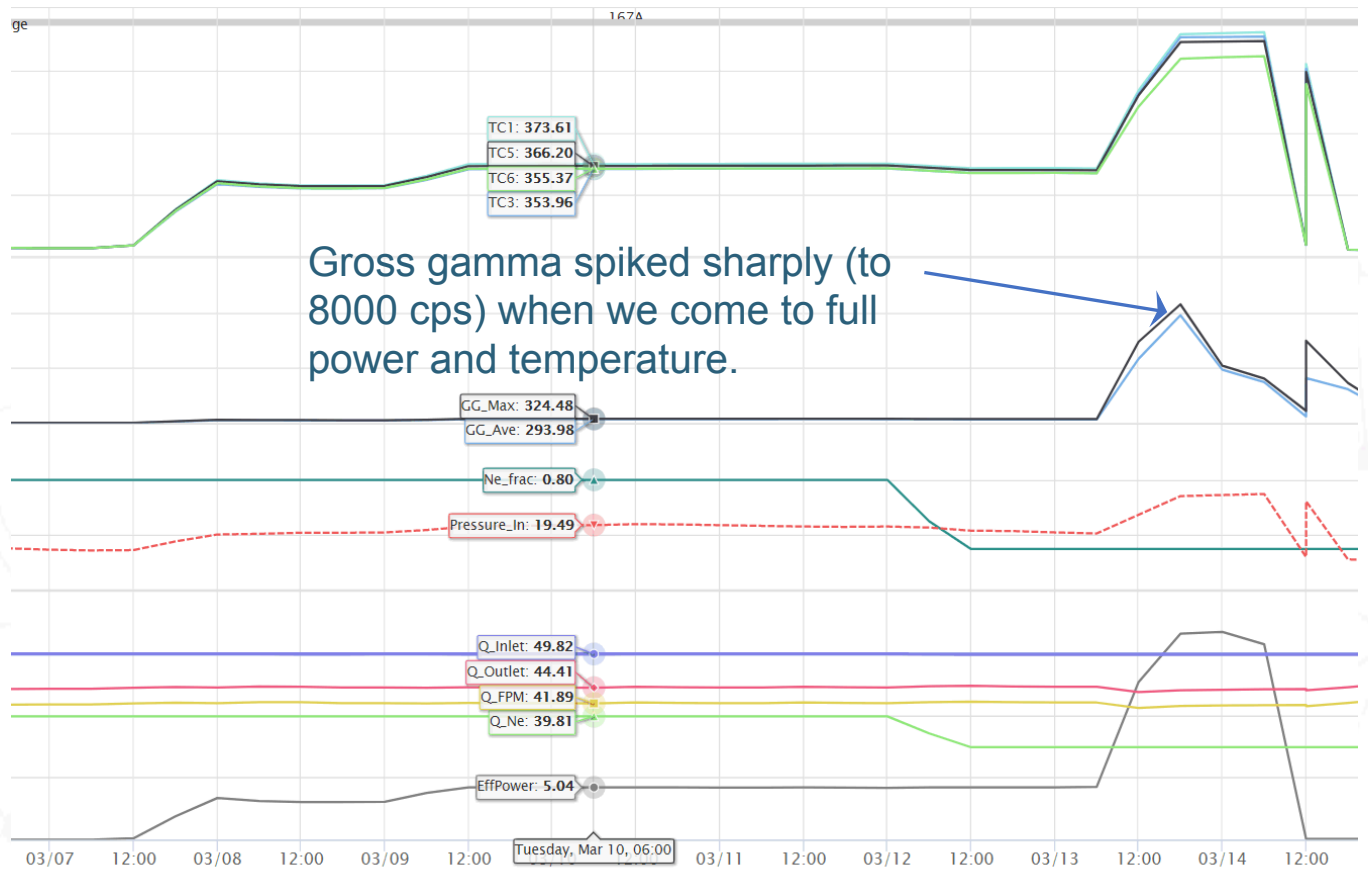




\section{ART}

$\mathrm{Ne}-23$ activation testing to verify backstreaming effect (during cycle 168A)

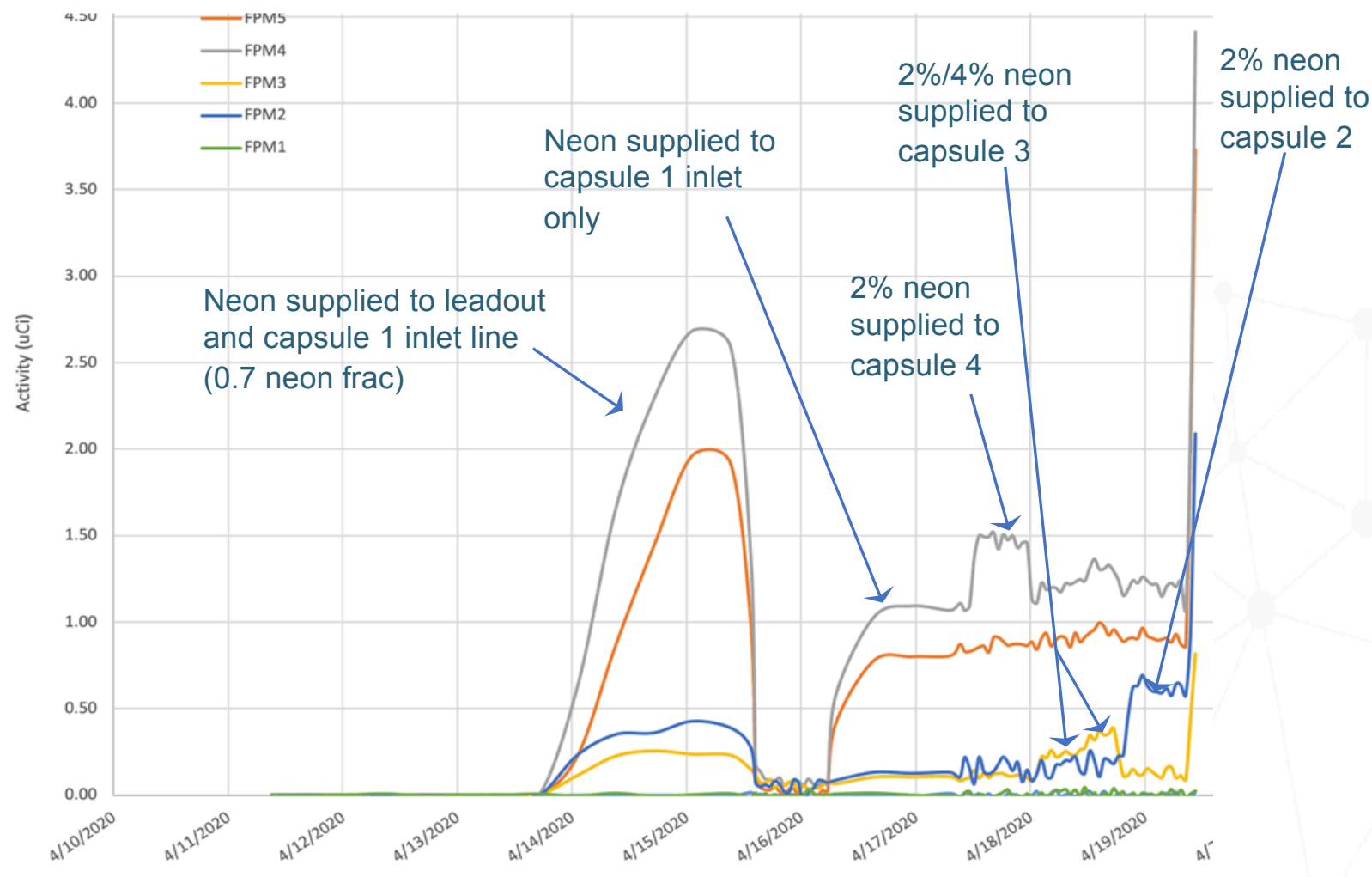




\section{ART:}

Increasing flow from capsules to leadout reduces gross gamma counts and presumably cross-talk
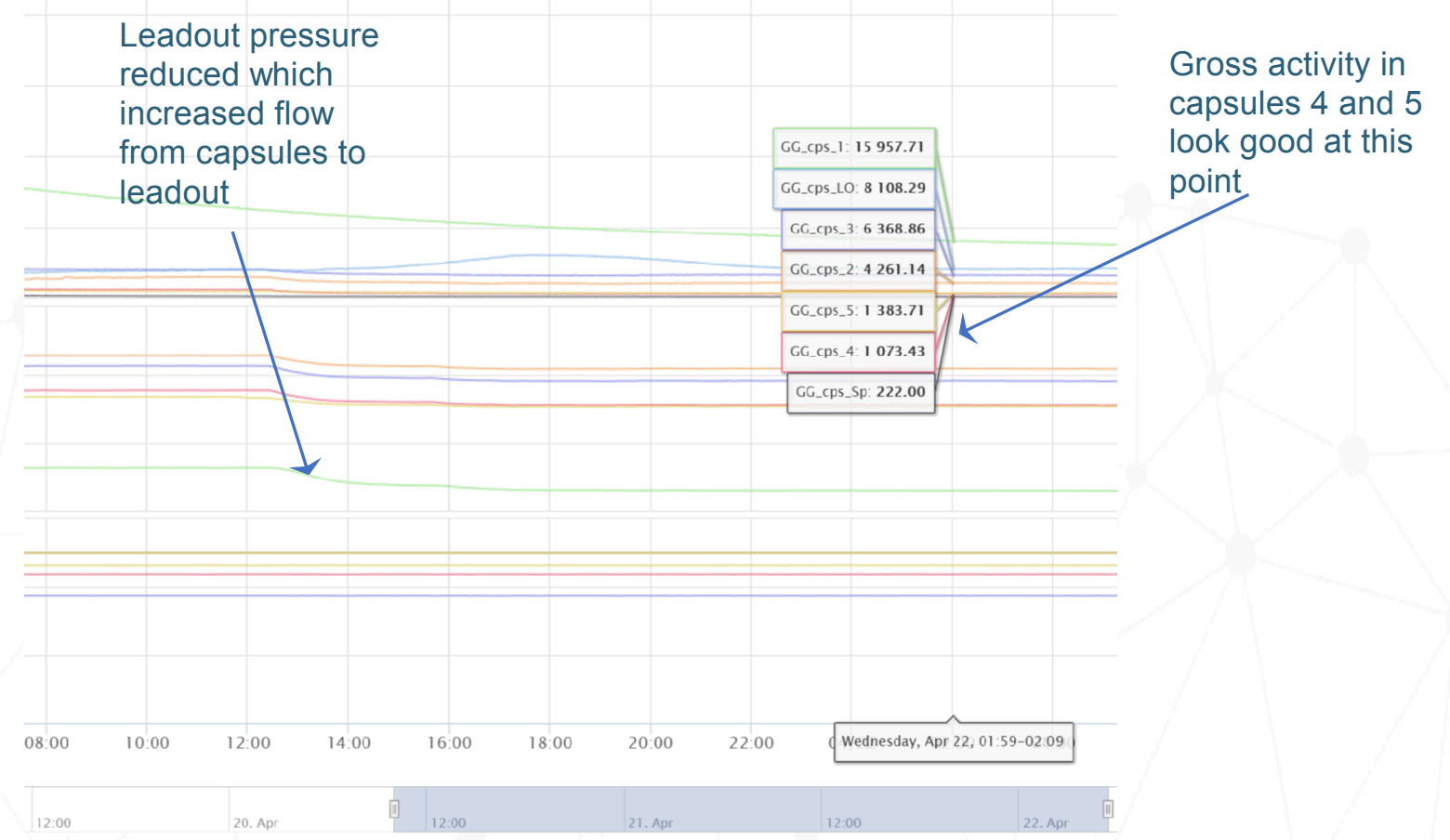


\section{Thermocouple summary as of last TCT meeting $(11 / 11 / 2019)$ which was the start of Cycle 166B}

\begin{tabular}{|c|c|l|}
\hline Capsule ID & $\begin{array}{c}\text { Number of TCs } \\
\text { Remaining } \\
(11 / 1 / 2019)\end{array}$ & Comments \\
\hline 5 & 3 & $\begin{array}{l}\text { These are the same three thermocouples with which we began } \\
\text { the test - no failures to date }\end{array}$ \\
\hline 4 & 4 & $\begin{array}{l}\text { These are the same four thermocouples with which we began } \\
\text { the test - no failures to date } \\
\text { One TC in the inner graphite fuel holder, and three in the outer } \\
\text { holder operating at a lower temperature }\end{array}$ \\
\hline 2 & 0 & Temperature controlled by calculated static gas blend \\
\hline 1 & 0 & Temperature controlled by calculated static gas blend \\
\hline
\end{tabular}




\section{Current thermocouple status (start of cycle 168B)}

\begin{tabular}{|c|c|l|}
\hline Capsule ID & $\begin{array}{c}\text { Number of TCs } \\
\text { Remaining } \\
(4 / 20 / 2020)\end{array}$ & \multicolumn{1}{c|}{ Comments } \\
\hline 5 & 3 & $\begin{array}{l}\text { These are the same three thermocouples with which we began } \\
\text { the test - no failures to date }\end{array}$ \\
\hline 4 & 4 & $\begin{array}{l}\text { These are the same four thermocouples with which we began } \\
\text { the test - no failures to date }\end{array}$ \\
\hline 3 & 0 & $\begin{array}{l}\text { One TC lasted through cycle 167A, but failed upon startup of } \\
\text { 168A. Temperature now controlled by calculated static gas } \\
\text { blend }\end{array}$ \\
\hline 2 & 0 & $\begin{array}{l}\text { Temperature controlled by calculated static gas blend } \\
\text { Temperature controlled by calculated static gas blend. But may } \\
\text { move to pure helium. }\end{array}$ \\
\hline
\end{tabular}




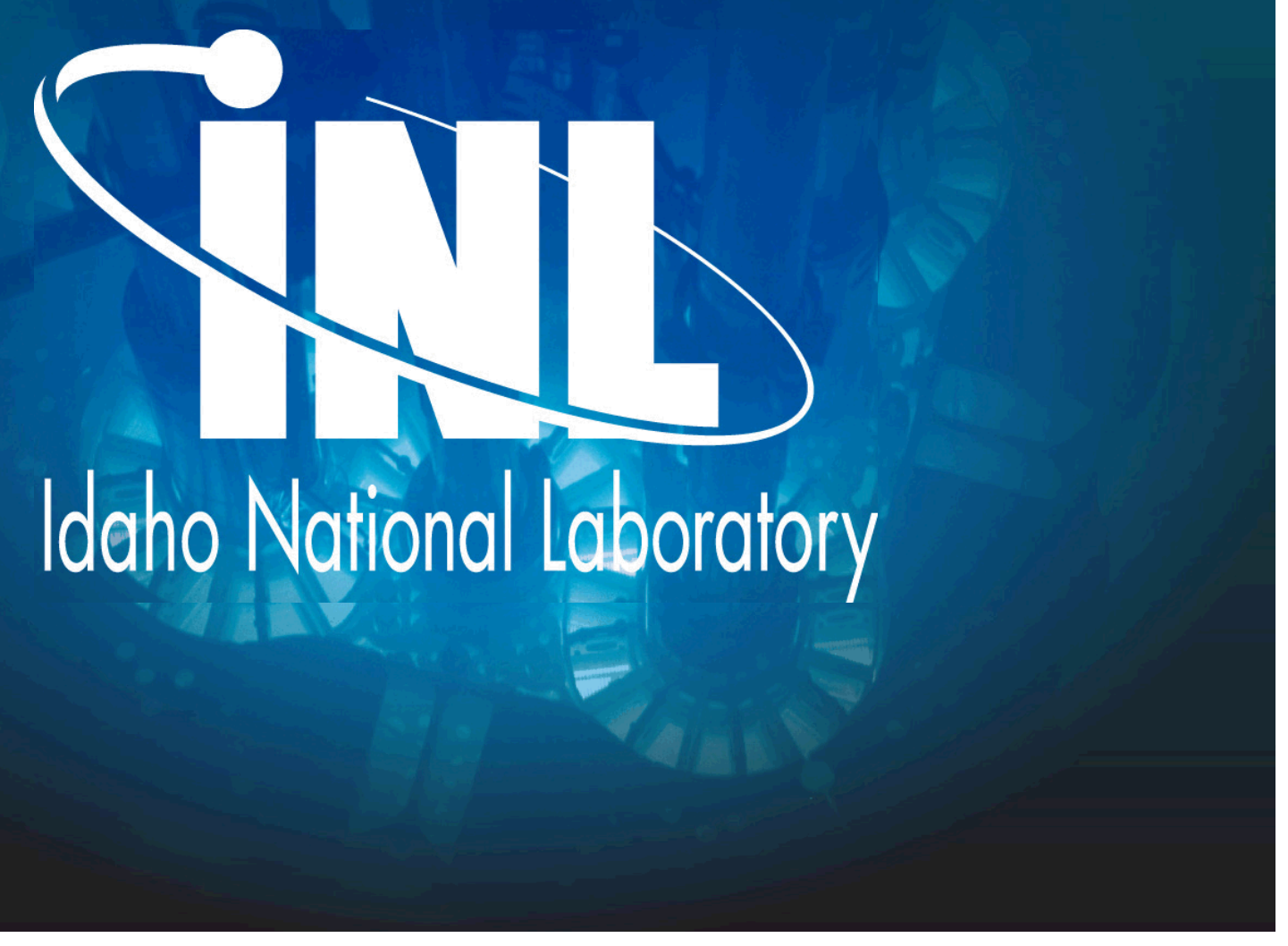

